\title{
Vigilância aos agrotóxicos: quantificação do uso e previsão de impactos na saúde-trabalho-ambiente para os municípios brasileiros
}

\author{
Surveillance on pesticides: quantification of use \\ and prediction of impact on health, work and the environment \\ for Brazilian municipalities
}

Wanderlei Pignati ${ }^{1}$

Noemi Pereira Oliveira ${ }^{2}$

Ageo Mário Cândido da Silva ${ }^{1}$

${ }^{1}$ Instituto de Saúde

Coletiva, Universidade Federal de Mato Grosso. Av. Fernando Corrêa da Costa 2367, Boa Esperança. 78060900 Cuiabá MT Brasil. pignatimt@gmail.com

${ }^{2}$ Faculdade de Odontologia, Centro Universitário de Várzea Grande.

\begin{abstract}
This paper analyzes the quantity, type and toxicity of pesticides used per hectare in the State of Mato Grosso as a surveillance strategy for the health of workers, the population in general and the environment, and to serve as a surveillance indicator for Brazilian cities. Brazil cultivated 95 million hectares in 2012, and Mato Grosso was the major consumer of pesticides. In this research, the database of the Agriculture and Livestock Defense Institute was consulted, as it records the prescribed agronomic data and place of use in sales invoices. The results reveal the average consumption of pesticides per hectare per crop: 12 liters for soy; 6 liters for corn; 4.8 liters for sugarcane; and 24 liters for cotton. The toxicological types and classes of pesticides used per hectare per crop were also monitored. Using a matrix of agricultural production and pesticide consumption, it was also found that certain health problems are correlated with the major producing regions. Based on pesticide consumption, agricultural production and pesticide toxicity it is possible to ascertain health problems in Brazilian cities and establish prevention and surveillance strategies for the workers, the environment and the populations exposed to pesticides.
\end{abstract}

Key words Pesticides, Health surveillance, Health, Work and environmental impacts
Resumo Como estratégia da vigilância em saúde do trabalhador, população e ambiente, foram analisadas as quantidades, os tipos e a toxicidade de agrotóxicos usados por hectare nas lavouras mato-grossenses para servir de apoio às vigilâncias dos municípios brasileiros. O Brasil cultivou 95 milhões de hectares de lavouras em 2012 e Mato Grosso foi o maior consumidor de agrotóxicos. Utilizaram-se dados do banco informatizado do Instituto de Defesa Agropecuário que registra nas notas fiscais de venda e local de uso e os dados dos receituários agronômicos. Os resultados mostraram que em média um hectare de soja consumiu 12 litros de agrotóxicos, o de milho 6 litros, o de cana 4,8 litros e o de algodão 24 litros. Verificaram-se também os tipos e classes toxicológicas usadas por hectare de cada lavoura. Também, verificou-se, através de uma matriz de produção agropecuária e consumo de pesticidas, que alguns agravos à saúde estão correlacionados com as regiões mais produtoras. A partir dos dados de consumo de agrotóxicos, pela produção agrícola $e$ da toxicidade desses venenos, podem-se inferir seus agravos e danos nos municípios brasileiros e estabelecer estratégias de prevenção e de vigilância à saúde dos trabalhadores, do ambiente e das populações expostas.

Palavras-chave Agrotóxicos, Vigilância à saúde, Impactos na saúde, Trabalho e ambiente 


\section{Introdução}

O processo produtivo do agronegócio, que se resume nas etapas do desmatamento, indústria da madeira, pecuária, agricultura, transporte, silagem, agroindústria, produção de sementes e insumos (combustíveis, agrotóxicos, fertilizantes químicos e calcários) causam várias situações de riscos nos vários ambientes desta cadeia produtiva. Vão além da saúde do trabalhador, englobando o meio ambiente, os alimentos, as águas e a saúde das famílias que moram nas fazendas ou nas cidades.

O Brasil é um dos maiores produtores de alimentos, algodão, madeira, celulose e biocombustível, mas também é o maior consumidor mundial de agrotóxicos. Na safra agrícola de 2012 foram pulverizados, nos seus 95 milhões de hectares de lavouras, cerca de 1,05 bilhões de litros de herbicidas, inseticidas e fungicidas, principalmente nos cultivos de soja, milho, cana de açúcar, algodão, cítricos, café e hortaliças ${ }^{1-3}$.

Dentre os vários impactos desta cadeia produtiva do agronegócio, os de maior relevância para a saúde do trabalhador, da população e do ambiente são as poluições e intoxicações agudas e crônicas relacionadas aos agrotóxicos. Neste processo agroquímico dependente, os fazendeiros, ao pulverizarem esses venenos, contaminam a lavoura, o produto, o meio ambiente, os trabalhadores e a população do entorno, com o objetivo de atingir o alvo ou as "pragas da lavoura" (inseto, fungo ou erva daninha) que se desenvolvem dentro das plantações ${ }^{1,4}$.

Trata-se de poluições (ambiental, ocupacional, alimentar) intencionais e não "derivas" que culpa o clima ou o trabalhador que pulveriza (tratorista ou piloto), além disso, sabe-se que no ato da elaboração do receituário e da compra que não existe agrotóxico não tóxico e que segundo estudos, apenas 30\% deles atingem o alvo e o restante vai para o solo, águas, ar e plantas ${ }^{5,6}$.

Segundo o SINDAG ${ }^{3}$ e Pelaez ${ }^{7}$, Mato Grosso é o maior consumidor nacional de agrotóxicos, representando 18,9\% do total, seguido de São Paulo (14,5\%), Paraná (14,3\%), Rio Grande do Sul (10,8\%), Goiás (8,8\%), Minas Gerais (9,0\%), Bahia (6,5\%), Mato Grosso do Sul (4,7\%), Santa Catarina (2,1\%) e 10,4\% pelos demais estados.

A utilização intensiva de agrotóxicos, através da pulverização por avião, trator ou equipamento manual, mesmo em total observância às Leis/ Normas, leva à poluição dos alimentos, das águas, do ar, das chuvas, do leite materno, do sangue e urina dos trabalhadores, população do entorno e dos animais, ou seja, contamina toda a biota, tanto na zona rural quanto urbana ${ }^{8-13}$.

A contaminação dos alimentos foi verificada pelas análises de 2.488 amostras de 20 cereais/ frutas/hortaliças coletadas no ano de 2012, em todas as capitais brasileiras, pelo Programa de Análise de Resíduos de Agrotóxicos em Alimentos (PARA) do Ministério da Saúde. De acordo com os resultados obtidos, $28 \%$ das amostras analisadas estavam insatisfatórias, ou seja, estavam contaminados acima dos Limites Máximos de Resíduos (LMR) e/ou seus resíduos encontrados não eram autorizados para aquelas culturas. Outras 35\% das amostras foram consideradas satisfatórias porque mesmo apresentando resíduos de agrotóxicos, estes estavam abaixo do LMR e apenas 37\% das amostras não continham resíduos desses tóxicos ${ }^{14}$.

O ciclo de produção agrícola implica na exposição humana (ambiental + ocupacional + alimentar) que poderá contaminar os trabalhadores e população e provocar vários agravos à saúde e que deverão sofrer processo de vigilância à saúde, serem diagnosticados, tratados e notificados a partir dos municípios brasileiros, via SINAN ${ }^{15}$. Além das intoxicações agudas, também são notificadas as intoxicações crônicas relacionadas aos agrotóxicos (alguns tipos de cânceres e malformações fetais, distúrbios neurológicos, endócrinos, mentais e cognitivos) ${ }^{16-27}$.

A busca de dados de consumo de agrotóxicos agrícola nos municípios brasileiros, por Princípio Ativo (PA) por hectare plantado dos vários tipos de lavouras, tem se tornado um desafio para os pesquisadores e instituições governamentais que cuidam da vigilância em saúde e/ou do ambiente. Isto se deve a vários fatores, entre eles: a) as indústrias fornecem para o Ministério da Agricultura, Pecuária e Abastecimento (MAPA) os dados anuais de quantitativos de agrotóxicos produzidos, estoque e vendas por estado, sendo que o acesso a esses dados não são livres; b) o receituário agronômico, obrigatório no ato da compra pelo consumidor, nem sempre está disponível para a consulta e em quase todos os estados brasileiros este instrumento não está informatizado; c) somente os estados de Mato Grosso, Minas Gerais e Paraná possuem um sistema específico e informatizado de registro, de compra, estoque, revenda e local de uso dos agrotóxicos.

O objetivo deste estudo foi mostrar a quantidade, tipos e Princípio Ativos (PA) dos agrotóxicos mais utilizados nas várias lavouras dos municípios de Mato Grosso para elaborar parâmetro de consumo desses tóxicos pulverizados 
nas lavouras dos municípios brasileiros e dar suporte na previsão dos seus impactos na saúde e se estabelecerem estratégias de vigilância à saúde dos trabalhadores, do ambiente e das populações expostas aos agrotóxicos.

Também, para melhorar o suporte estratégico às Vigilâncias dos municípios, se verificou através de outros estudos e de uma matriz de produção agropecuária e consumo de pesticidas, que os agravos à saúde estão correlacionados com os municípios e regiões mais produtoras, assim como coincidem com os meses das safras e proximidade das lavouras. Discutiram-se também os desrespeitos às legislações, uso inseguro e transição agroecológica.

\section{Metodologia}

A metodologia executada foi de análise descritiva, estatística e de distribuição espacial por município dos dados de agrotóxicos consumidos em Mato Grosso que se encontram no banco de dados do Sistema de Informação de Agrotóxicos (SIA) do Instituto de Defesa Agropecuário (INDEA) que registra, desde 2005, os dados dos receituários agronômicos nas notas fiscais emitidas pelas casas revendedoras que enviam on-line para o escritório estadual do INDEA em Cuiabá ${ }^{28}$. Nele se registra o nome da empresa e o município da revenda, o local de consumo (nome da fazenda e município), o nome do produto comercial e o(s) PA(s), a patologia ("praga") a combater, a forma de pulverização (avião, trator e manual), o número de hectares a serem tratados, o tipo de lavoura, o mês e o ano de compra e mês e ano de uso. Os pesquisadores tiveram acesso ao banco eletrônico de uma série histórica de dados desse Sistema, dos anos de 2005 a 2012. Os dados foram selecionados e extraídos a partir da base do local (município) onde foram usados os agrotóxicos.

No banco de dados do IBGE-SIDRA ${ }^{2}$ se buscou o total de hectares plantados de cada lavoura temporária de soja, milho, algodão e cana, por município de Mato Grosso, referente ao ano de 2012 e selecionaram-se os dez municípios maiores produtores. Como esse banco fornece os dados pela área plantada e toneladas colhidas, escolhemos a modalidade de dados de área plantada, pois é a partir desta, do tipo de cultura e da patologia agrícola que os agrônomos escolhem os tipos e as quantidades de agrotóxicos a serem pulverizados.

A soja, o milho, o algodão e a cana foram escolhidos pelo critério de área de cobertura dessas lavouras, que representaram $90 \%$ do total de lavouras do estado de Mato Grosso e 80\% do Brasil da safra de 2012, segundo IBGE-SIDRA².

A seleção dos três grupos de agrotóxicos classificados pela ação, ou seja, os herbicidas, inseticidas e fungicidas, se devem ao fato de que na análise preliminar desse banco de dados do INDEA-MT ${ }^{28}$ (2013), essas três classes representaram 95\% do total de agrotóxicos consumidos, os quais estão distribuídos da seguinte maneira: herbicidas com $60 \%$, inseticidas com $21 \%$ e fungicida com $14 \%$ e outros com consumo de $5 \%$.

\section{Resultados}

No ano de 2012, no estado de Mato Grosso se plantou 6,6 milhões de hectares de soja; 2,7 milhões de milho; 0,9 milhões de algodão; 0,4 milhões de cana; 0,2 milhões de arroz; 0,4 milhões de hectares de outros (feijão, girassol, borracha, café, frutas e verduras) e se consumiu/pulverizou cerca de 140,8 milhões de litros de agrotóxicos (produto formulado) de herbicidas, inseticidas e fungicidas ${ }^{2,28}$.

Esses dados de consumo de agrotóxicos (litros) do banco de dados do INDEA-MT foram distribuídos por município conforme Figura 1 e os dados de produção agrícola (hectares), do banco do IBGE-SIDRA também foram distribuídos por município conforme Figura 1 e verificou-se que a região de Sinop, Rondonópolis e Tangará concentraram 70\% da produção agrícola e consumiram $70 \%$ dos agrotóxicos.

Desses conjuntos de dados, selecionaram-se os municípios maiores produtores de soja, milho, algodão e cana de açúcar e seus consumos de agrotóxicos e realizou-se um cruzamento de dados alocando-os na Tabela 1.

Quando se analisou a Tabela 1, verificou-se que o consumo de agrotóxicos por hectare de lavoura de soja variou de 7,5 a 16,8 litros, sendo que na lavoura de milho variou de 3,0 a 9,6 litros por hectare e para o cultivo de cana de açúcar variou de 3,7 a 7,6 litros por hectare e na cultura de algodão, o consumo variou de 17,5 a 44,9 litros por hectare. Isto se deve a diversos fatores, como: infestação maior ou menor de patologias agrícolas, aumento da resistência das pragas aos agrotóxicos e também porque algumas plantas transgênicas (soja RR) usam maiores quantidades de pesticidas que as tradicionais.

Porém, para facilitar os cálculos a serem usados em estimativas em outros estados e municípios brasileiros, usamos o indicador de quanti- 


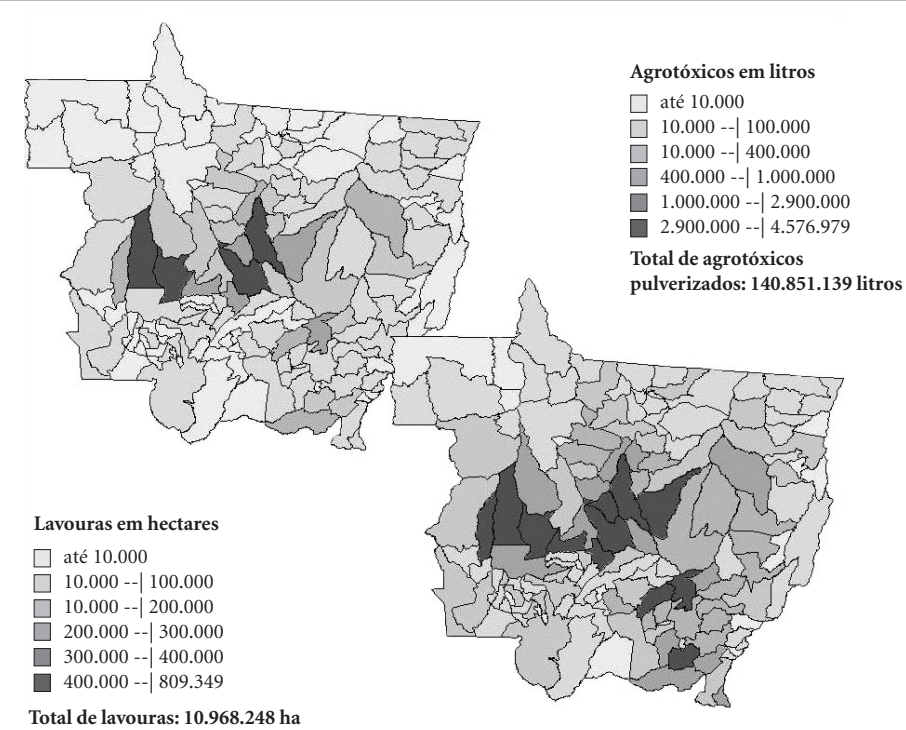

Figura 1. Lavouras e consumo de agrotóxicos por município no MT em 2012.

Fontes: IBGE-SIDRA 2013²; INDEA-MT $2013^{28}$.

Tabela 1. Produção agrícola (mil hectares) dos maiores produtores e seus consumos de agrotóxicos (Mil litros) por tipo de lavoura; Mato Grosso, 2012.

\begin{tabular}{|c|c|c|c|c|c|c|c|c|}
\hline \multirow[b]{2}{*}{ Município } & \multicolumn{2}{|c|}{ Soja } & \multicolumn{2}{|c|}{ Milho } & \multicolumn{2}{|c|}{ Algodão } & \multicolumn{2}{|c|}{ Cana } \\
\hline & Ha. & Agrotx & Ha. & Agrotx & Ha. & Agrotx & Ha. & Agrotx \\
\hline Sorriso & 543 & 4.348 & 228 & 925 & 21 & 412 & 0,3 & 1,4 \\
\hline Sapezal & 325 & 5.127 & 114 & 723 & 62 & 1.085 & - & - \\
\hline Nova Mutum & 310 & 3.402 & 101 & 970 & 24 & 577 & - & 131 \\
\hline Campo N. do Parecis & 298 & 4.241 & 87 & 647 & 33 & 603 & 28,4 & $\begin{array}{r}131 \\
38\end{array}$ \\
\hline Diamantino & 277 & 4.038 & 50 & 482 & 37 & 887 & 6,6 & 30 \\
\hline Lucas do Rio Verde & 216 & 2.928 & 175 & 532 & 4,9 & 119,5 & - & 09 \\
\hline Nova Ubiratã & 206 & 1.537 & 63 & 427 & 6,4 & 154,4 & 0,2 & , \\
\hline Primavera do Leste & 200 & 3.059 & 70 & 570 & 46 & 1.492 & - & 24 \\
\hline Itiquira & 180 & 2.102 & 31,9 & 191,4 & 8,8 & 212,2 & 5 & $\begin{array}{l}24 \\
32\end{array}$ \\
\hline Campos de Júlio & 152 & 1.512 & 71 & 683 & 21 & 387 & 6,5 & 02 \\
\hline Alto Garças & 84 & 1008 & 16,9 & 101,8 & 19 & 378 & 0,1 & $\begin{array}{r}0,1 \\
181\end{array}$ \\
\hline Barra dos Bugres & 3,5 & 42 & 0,6 & 3,6 & - & - & 44,1 & 01 \\
\hline Campo Verde & 145 & 1740 & 69 & 359 & 74 & 1.614 & 0,1 & $\begin{array}{r}0,1 \\
113\end{array}$ \\
\hline Denise & - & - & 0,1 & 0,48 & - & - & 26,8 & 113 \\
\hline Jaciara & 30 & 360 & 11,7 & 69,9 & 2,1 & - & 16,9 & $\begin{array}{l}63 \\
47\end{array}$ \\
\hline Lambari D'Oeste & 0,9 & 10,8 & 0,3 & 1,5 & - & - & 11,2 & $\begin{array}{r}4 / \\
198\end{array}$ \\
\hline Nova Olímpia & - & - & 1,2 & 7,2 & - & - & 25,9 & $\begin{array}{r}190 \\
0.5\end{array}$ \\
\hline Pedra Preta & 41,5 & 498 & 12,5 & 75 & 29 & 1.301 & 0,1 & $\begin{array}{r}0,5 \\
55\end{array}$ \\
\hline São José do Rio Claro & 85,4 & 1025 & 16 & 96 & 1,5 & 35,8 & 8,3 & 55 \\
\hline Tangará da Serra & 49,7 & 595,8 & 13,8 & 82,8 & 3,5 & 84,9 & 14 & \\
\hline
\end{tabular}

Fontes: IBGE-SIDRA 2013²; INDEA-MT $2013^{28}$.

dade média de agrotóxicos utilizados por hectare nas respectivas lavouras desses maiores produtores do estado de Mato Grosso no ano de 2012, conforme Tabela 2.
Os dados da Tabela 2 mostram que um hectare de soja consumiu 12,17 litros de agrotóxicos, um hectare de milho consumiu 6,14 litros, um hectare de algodão consumiu 23,86 litros e um 
hectare de cana de açúcar consumiu 4,84 litros de agrotóxicos em forma de produto formulado, principalmente dos tipos: herbicida, fungicida e inseticida.

Através do calendário agrícola foram definidos os meses de aplicação de agrotóxicos de acordo com o tipo de lavoura. Os dados da Tabela 2 foram alocados neste calendário, que resultou na distribuição dos dados da Tabela 3. O calendário agrícola é um instrumento de consulta que fornece detalhadamente a forma correta de se plantar mais de 20 culturas no Estado de Mato Grosso, e que tem por objetivo orientar a melhor época para realizar as atividades agrícolas em cada fase da cultura com orientações técnicas de plantio, tratos culturais, adubação, início da colheita, secagem, informações climáticas e outras a serem seguidas em cada mês, ou seja, de janeiro a dezembro ${ }^{29}$.

Verifica-se nesta tabela que, de acordo com calendário agrícola executado, o período de intersafra foi de junho a setembro, quando não há aplicação de agrotóxicos, predominando o clima seco e sem chuvas, conformando a época onde se cultiva apenas a cana de açúcar. Esse período da intersafra da soja, milho e algodão, também é chamado de "vazio sanitário", que de acordo com Decreto n. 1524 de 20/08/2008 do Governo do estado de Mato Grosso, fica proibido a plantação

Tabela 2. Produção agrícola, consumos de agrotóxicos, médias de usos por hectare e tipos de lavouras dos 10 municípios maiores produtores de Mato Grosso no ano de 2012.

\begin{tabular}{lrrr}
\hline \multicolumn{1}{c}{ Cultura } & Hectares & Agrotóxicos & Média \\
\hline Soja & 2.852 .509 & 34.737 .949 & 12,17 \\
Milho & 1.028 .533 & 6.318 .576 & 6,14 \\
Algodão & 371.334 & 8.861 .720 & 23,86 \\
Cana-de-açúcar & 188.816 & 914.955 & 4,84 \\
\hline
\end{tabular}

Fontes: IBGE-SIDRA 2013²; INDEA-MT $2013^{28}$. e irrigação dessas lavouras para prevenção de diversas patologias, entre elas a ferrugem asiática da soja (Phakopsorapachyrhizi) e o bicudo do algodoeiro (Anthonomusgrandis).

Em todas as lavouras estudadas são utilizados mais de um tipo de agrotóxicos e como em cada município são cultivadas várias lavouras concomitantemente, isto implica numa exposição múltipla aos agrotóxicos, tanto dos trabalhadores e da população do entorno, quanto de toda biota, podendo elevar os riscos de doenças humanas e ambientais relacionadas aos agrotóxicos.

Para o detalhamento dos princípios ativos utilizados foram selecionados quatro municípios entre os 10 maiores produtores listados na Tabela 1, buscando no banco do IBGE-SIDRA ${ }^{2}$ suas produções agrícolas do ano de 2012. Elegeram-se os municípios de Lucas do Rio Verde e Campo Verde que cultivaram soja, milho e algodão e, para o cálculo de uso de agrotóxicos por hectare na cana de açúcar, selecionaram-se os municípios de Barra do Bugre e Nova Olímpia que cultivaram apenas esse produto. Em seguida, analisou-se no Banco de Dados do INDEA-MT ${ }^{28}$ o consumo dos principais PA dos agrotóxicos utilizados nessas lavouras, mostrados na Tabela 4. Esses 31 tipos diferentes de PA de agrotóxicos mais utilizados representaram o consumo de $90 \%$ de um total de 202 tipos diferentes empregados nas lavouras destes municípios durante o ano de 2012.

Para se estimar o potencial dos impactos dos Princípios Ativos desses agrotóxicos na saúde, verificaram suas classes toxicológicas humanas (I extremamente tóxico, II altamente tóxico, III medianamente tóxico e IV pouco tóxico) e riscos ambientais (I extremamente perigoso, II altamente perigoso, III medianamente perigoso e IV pouco perigoso) também alocados na Tabela 4 .

Verifica-se na Tabela 4 que a lavoura de soja usou maior quantitativo de herbicidas por hectare (9,0 litros), seguido de inseticidas (2,4 litros) e fungicidas ( 1,1 litros). As culturas de milho também usaram mais herbicidas por hectare

Tabela 3. Quantidade média em litros de agrotóxicos aplicados por mês para cada hectare plantado de soja, milho, algodão e cana-de-açúcar em Mato Grosso, 2012.

\begin{tabular}{|c|c|c|c|c|c|c|c|c|c|c|c|c|c|}
\hline Lavouras & Jan & Fev & Mar & Abril & Maio & Jun & Jul & Ago & Set & Out & Nov & Dez & Total \\
\hline Soja & 3 & & & & & & & & 3 & 3 & 3 & 3 & 12 \\
\hline Milho & & 1,5 & 1,5 & 1,5 & 1,5 & & & & & & & & 6 \\
\hline Algodão & & 6 & 6 & 6 & 6 & & & & & & & & 24 \\
\hline Cana & 0,6 & 0,6 & 0,6 & 0,6 & 0,6 & & & & 0,6 & 0,6 & 0,6 & 0,6 & 4,8 \\
\hline
\end{tabular}

Fontes: INDEA-MT 201328; IBGE-SIDRA 2013²; EMPAER-MT $2013^{29}$ (Calendário Agrícola). 
Tabela 4. Consumo dos agrotóxicos (litros) por Princípio Ativo por hectare de soja, milho, algodão e cana de açúcar em municípios selecionados de Mato Grosso em 2012.

\begin{tabular}{|c|c|c|c|c|c|c|c|c|c|c|c|}
\hline \multirow[b]{2}{*}{$\begin{array}{l}\text { Princípio } \\
\text { ativo }\end{array}$} & \multirow[b]{2}{*}{ Uso $^{*}$} & \multirow[b]{2}{*}{$\begin{array}{l}\text { Clas. } \\
\text { toxic. }\end{array}$} & \multirow[b]{2}{*}{$\begin{array}{l}\text { Risco } \\
\text { Amb. }\end{array}$} & \multicolumn{2}{|c|}{ Soja } & \multicolumn{2}{|c|}{ Milho } & \multicolumn{2}{|c|}{ Algodão } & \multicolumn{2}{|c|}{ Cana } \\
\hline & & & & $\begin{array}{c}\text { Campo } \\
\text { Verde }\end{array}$ & $\begin{array}{c}\text { Lucas } \\
\text { Rio } \\
\text { Verde }\end{array}$ & $\begin{array}{l}\text { Campo } \\
\text { Verde }\end{array}$ & $\begin{array}{c}\text { Lucas } \\
\text { Rio } \\
\text { Verde }\end{array}$ & $\begin{array}{c}\text { Campo } \\
\text { Verde }\end{array}$ & $\begin{array}{c}\text { Lucas } \\
\text { Rio } \\
\text { Verde }\end{array}$ & $\begin{array}{c}\text { Barra } \\
\text { do } \\
\text { Bugres }\end{array}$ & $\begin{array}{c}\text { Nova } \\
\text { Olímpia }\end{array}$ \\
\hline $2,4 \mathrm{D}$ & $\mathrm{H}$ & I & III & 0,9 & 1,1 & 0,1 & 0,1 & - & - & 0,3 & 0,2 \\
\hline Acefato & I & II & III & 0,1 & 0,1 & - & - & 0,2 & 0,8 & - & - \\
\hline Amicarbe & $\mathrm{H}$ & III & III & - & - & - & - & - & - & - & 0,1 \\
\hline Atrazina & $\mathrm{H}$ & III & III & - & - & 3,4 & 3,7 & - & - & - & - \\
\hline Azafenidin & $\mathrm{H}$ & III & III & - & - & - & - & - & - & - & 0,2 \\
\hline Carbofurano & I & I & II & - & - & 0,1 & 0,1 & 0,1 & - & - & 0,3 \\
\hline Carbendazin & $\mathrm{F}$ & II & III & 0,2 & 0,2 & - & - & 0,2 & 0,1 & 0,2 & 0,2 \\
\hline Cipermetrina & I & III & II & 0,2 & 0,1 & - & - & - & 0,2 & - & - \\
\hline Clomazona & $\mathrm{H}$ & II & II & 0,1 & - & - & - & 3,5 & 4,1 & - & 0,2 \\
\hline Clorpirifós & I & I & I & - & 0,1 & 0,2 & 0,3 & 6,1 & 6,4 & - & - \\
\hline Diuron & $\mathrm{H}$ & III & II & - & - & - & - & 0,7 & 1,7 & 0,4 & 0,5 \\
\hline Endosulfan & I & I & I & 1 & 0,5 & 0,4 & 0,5 & 3,6 & 3,1 & - & - \\
\hline Etefom & $\mathrm{RC}$ & II & II & 0,1 & - & - & - & 0,6 & 1,4 & 0,2 & - \\
\hline Fipronil & I & II & II & 0,1 & 0,1 & - & - & 0,1 & 0,1 & - & - \\
\hline Flutriafol & $\mathrm{F}$ & II & III & 0,2 & 0,3 & - & - & - & - & - & - \\
\hline Glifosato & $\mathrm{H}$ & IV & III & 4,9 & 6,1 & 0,2 & 0,6 & - & - & 0,8 & 1,8 \\
\hline Imazapic & $\mathrm{H}$ & II & III & - & - & - & - & - & - & 0,1 & - \\
\hline Isoxaflutol & $\mathrm{H}$ & III & II & - & - & - & - & - & - & 0,1 & 0,1 \\
\hline Malation & $\mathrm{I}$ & III & III & - & - & - & - & 0,6 & - & - & - \\
\hline Metamidofós & I & I & II & 1,3 & 1,2 & - & - & 0,4 & 0,9 & - & - \\
\hline MetilParatio & I & I & III & 1 & 0,4 & - & - & 0,1 & 1,2 & - & - \\
\hline Metomil & I & I & II & - & - & 0,3 & 0,1 & 0,8 & 1,9 & - & - \\
\hline Metribuzin & $\mathrm{H}$ & IV & II & - & - & - & - & - & - & 0,5 & 0,5 \\
\hline MSMA & $\mathrm{H}$ & III & III & - & - & - & - & - & 0,8 & 0,1 & 0,4 \\
\hline Óleo mineral & A & IV & III & 0,2 & 0,2 & - & - & 1,5 & 0,2 & - & - \\
\hline Paraquate & $\mathrm{H}$ & I & II & 0,3 & 0,3 & - & - & 0,6 & - & - & - \\
\hline PermetrinaS & I & III & II & - & 0,1 & - & - & - & - & 0,3 & 0,2 \\
\hline Metolacloro & $\mathrm{H}$ & I & II & 0,4 & - & - & - & 0,5 & 0,5 & - & - \\
\hline Tebutiurom & $\mathrm{H}$ & II & II & - & - & - & - & - & - & 0,2 & 0,6 \\
\hline Tebuconazol & $\mathrm{F}$ & III & II & 0,7 & 0,5 & 0,2 & 0,2 & - & - & - & - \\
\hline Triflurallina & $\mathrm{H}$ & II & II & 0,8 & - & - & - & 2,1 & 3,1 & 0,4 & 0,6 \\
\hline Total & & & & 12,6 & 11,1 & 4,9 & 5,6 & 21,7 & 26,5 & 3,6 & 5,9 \\
\hline
\end{tabular}

" Observação: $\mathrm{H}$ = herbicida. $\mathrm{I}$ = inseticida, $\mathrm{F}=$ Fungicida, $\mathrm{A}=$ Adjuvante, $\mathrm{RC}=$ Regulador de crescimento. Fontes: INDEA-MT, 201328; IBGE-SIDRA $2013^{2}$.

(4,3 litros), seguido de inseticidas (1,0 litros) e fungicidas (0,2 litros). Enquanto que as culturas de algodão usaram mais inseticidas por hectare (14,1 litros), seguido de herbicidas (8,8 litros) e fungicidas (0,15 litros). As lavouras de cana de açúcar usaram 4,2 litros de herbicidas por hectare, incluindo o glifosato como maturador e também se usou 0,4 litros de inseticidas e 0,2 litros de fungicidas/hectare.

Também se verificou no Banco de Dados do $\operatorname{INDEA}^{28}$ que em relação à toxicidade humana dos agrotóxicos, os consumos e/ou pulverizações naquelas lavouras apresentaram os seguintes resultados: a classe I de $40 \%$, os da classe II de $23 \%$, os da classe III de $17 \%$ e os da classe IV de 20 $\%$. Apesar de apresentarem diferenças quanto ao tipo de cultura (soja, milho, algodão e cana), isto poderá ser mais um fator que aumentará os riscos para a saúde humana, implicando em maiores cuidados na prevenção e precaução dos seus usos.

Esses agrotóxicos consumidos nessas lavouras têm potencialidade de causar intoxicações agudas e quando a Dose Letal média (DL 50) de cada um deles ultrapassar o nível tolerável poderá ser fatal para a vida. Além disso, para cada um desses agrotóxicos existem estudos demonstrando seus efeitos na saúde humana, seja de indução/promoção de vários tipos de cânceres, más 
formações fetais, desregulação endócrina, distúrbios imunológicos e perturbações mentais ${ }^{30-33}$.

Outros estudos demonstram que esses agrotóxicos também têm a potencialidade de aderirem às plantas e/ou serem absorvidos por elas e contaminarem suas produções, conforme dados demonstrados no PARA 2012. Assim como outros estudos mostram, podem se dispersar, seja por evaporação ou desvio das gotas/nuvens ou lixiviação e contaminarem as águas superficiais, as águas subterrâneas, a chuva e o ar que respi$\operatorname{ramos}^{9,12}$.

Portanto, é necessário discutir estes dados e suas consequências para a saúde pública em sua relação com o modelo de desenvolvimento econômico brasileiro, com o modo de produção do agronegócio dependente de agroquímicos (transgênicos, agrotóxicos e fertilizantes), com o uso inseguro dos agrotóxicos, com seus subsídios fiscais, com o aumento da concentração de terras e com a disputa com os movimentos de busca de um modelo de desenvolvimento sustentável para o campo baseado na agroecologia.

\section{Discussão}

Esta estratégia metodológica de se analisar a produção agropecuária, o uso de agrotóxicos e seus efeitos na saúde-ambiente, contribuirá para a produção de informações que subsidiarão estratégicas de precaução de impactos e de prevenção nas ações de vigilância em saúde, em todos os seus componentes, saúde do trabalhador, ambiental, sanitária e epidemiológica e colaborarão na reflexão do modelo de desenvolvimento executado no Brasil pelos Governos e classe patronal, a qual impacta principalmente os trabalhadores e o ambiente.

Como por exemplo, as previsões de contaminação ambiental e intoxicações humanas poderão ser inferidas conforme o tipo de lavoura predominante no município (soja, milho, cana e algodão), os tipos de agrotóxicos utilizados e suas toxidades agudas e crônicas, servindo de alerta aos agentes da vigilância em saúde. Estes dados, em conjunto com a estimativa de periodicidade de uso, são importantes também para a identificação dos meses de maior emprego nas comunidades com maior probabilidade de exposição. Ajudarão no estabelecimento de prioridades para as atuações conjuntas de prevenção e monitoramento dos órgãos públicos (Saúde, Agricultura e Ambiente), sociedade civil e populações expostas. Também colaborarão na previsão de "eventos sentinelas", em toda a rede assistencial (hospitais, PS, PSF e Ambulatórios).

Com os dados de prováveis intoxicações agudas e crônicas e contaminação ambiental e alimentar, os municípios, complementando com suas informações socioeconômicas locais, poderão construir um mapa dos possíveis impactos gerados pelo uso dos agrotóxicos com localização das comunidades rurais e urbanas mais ou menos vulneráveis. E com participação da representação dos trabalhadores e população, se poderá implementar processos de conhecimento, discussão da situação sanitária e organização da sociedade para executar uma vigilância a saúde efetiva como relatado por Pignati et al. ${ }^{8}$, Augusto et al. ${ }^{34}$ e Rigotto et al. ${ }^{35}$ ou como proposto por Porto e Soares ${ }^{36}$ ou por Machado ${ }^{37}$.

Na produção de “informação para a ação" e para aumentar as evidências científicas dos impactos dos agrotóxicos na saúde, pode-se conformar uma matriz de produção agrícola, uso de agrotóxicos e incidência de agravos de uma série histórica dos últimos dez anos, de cada Unidade Federada, como apresentado em Pignati e Machado $^{21}$ e Pignati et al. ${ }^{5}$.

Esses autores verificaram os dados de morbimortalidade numa matriz de produção e agravos, em série histórica de 10 anos (2001 a 2012), mostrando a correlação da produção (hectares por habitante), a exposição aos agrotóxicos (litros por habitante) e as incidências de agravos correlacionados. Os Acidentes de Trabalho/1000 trabalhadores, as Intoxicações agudas/100.000 habitantes, os Cânceres/10.000 habitantes e as Malformações/1000 nascidos vivos, apresentaram correlações positivas nos testes bioestatísticos.

Com estes dados organizados por regional de saúde, comparando as regiões mais produtoras agrícolas com as menos, como mostradas na Figura 1, se verificou que as incidências de intoxicações agudas e de alguns cânceres e más-formações, apresentaram os maiores níveis significativos nas três regiões mais produtoras agrícolas já citadas, ou seja, na de Sinop, de Rondonópolis e de Tangará da Serra ${ }^{15,20,24-26}$.

Também foi evidenciado por Fávero ${ }^{22}$, a correlação do uso de agrotóxicos nas lavouras e o aumento das incidências de doenças pulmonares agudas em crianças menores de 5 anos atendidas nas Unidades de Saúde nos períodos da safra da soja, milho e algodão. Pois se verificou que dentre os pesticidas mais usados, vários são alergênicos e irritantes pulmonar. Além disso, este estudo também mostrou que quanto mais perto das lavouras se situavam as residências das crianças, 
maior era o nível endêmico das patologias do trato respiratório.

Esta problematização de riscos, também servirá para prever a contaminação do leite materno das mães (trabalhadoras rurais e urbanas) que amamentam num determinado município, conforme Palma ${ }^{11}$, ou a contaminação do sangue e urina de professores das escolas rurais rodeadas de lavouras ou na periferia da cidade, os quais se expõem aos agrotóxicos via ar, água potável e chuva descritos em Moreira et al. ${ }^{12} \mathrm{e}$ Belo et al. ${ }^{13}$.

Nas observações dos estudos acima, se verificou que as pulverizações daqueles 140,8 milhões de litros de agrotóxicos por avião e trator eram realizadas a menos de 10 metros de fontes de água potável, córregos, de criação de animais e de residências ${ }^{8,12,13}$. Essas distâncias desrespeitavam o antigo Decreto de Mato Grosso n.2283/09 que proibia a pulverização por trator a 300 metros ou o atual Decreto de Mato Grosso n.1651/13 que cancelou o anterior, mas que pró́be pulverização por trator a 90 metros daqueles locais. Também desrespeitavam a Instrução Normativa do MAPA $n^{\circ}$ 02/2008 que proíbe pulverização aérea a 500 metros de fontes de água potável, córregos, de criação de animais e de residências. Portanto, além dos fazendeiros não respeitarem as legislações e as Normas de pulverização de agrotóxicos, o Governo pouco fiscaliza e ainda amplia os riscos, diminuindo a margem operacional de pulverização proibida, por trator, de 300 para 90 metros.

Essa metodologia poderá ser utilizada em outros municípios e regiões do Brasil. A primeira medida seria organizar os dados de produção agropecuária através do banco de dados do IBGE-SIDRA ${ }^{2}$ e estimar o uso de agrotóxicos através dos dados das Tabelas 2 e 4, verificar as toxidades agudas e crônicas nas bibliografias existentes e inferir seus impactos na saúde e no ambiente do município.

Além dos dados e metodologia mostrados neste artigo, será necessário complementar com outras informações de saúde, do ambiente e do processo produtivo agropecuário para inferirmos impactos específicos de acordo com situações loco regionais, como por exemplo: mapeamento de áreas de deriva das pulverizações, descrição das atividades laborais, dados de intoxicações agudas e crônicas, verificação das normas sanitárias existentes e conformação dos instrumentos e ações do controle social na saúde, agricultura e ambiente.

As informações produzidas por meio dessa metodologia são importantes também para os processos de educação em saúde junto às populações expostas, trabalhadores e entidades componentes do controle social visando o fortalecimento das ações de vigilância. Da mesma forma, poderão subsidiar ações integradas dos órgãos de fiscalização da agricultura, meio ambiente, trabalho, saúde, entre outros, que são fundamentais para o avanço da vigilância dos impactos dos agrotóxicos em níveis locais e buscar a diminuição progressiva de seu uso, indo na transição de outro modelo agropecuário que poderá ser o agroecológico, como propõe a Campanha Permanente Contra os Agrotóxicos e pela Vida ${ }^{38}$ e a Carta Política aprovada em maio de 2014 no III Encontro Nacional de Agroecologia ${ }^{39}$.

Nessa direção, a estratégia metodológica agrega aspectos importantes para se operacionalizar as diretrizes da Política Nacional de Saúde do Trabalhador e da Trabalhadora ${ }^{40}$, da Política Nacional de Saúde Integral das Populações do Campo e da Floresta ${ }^{41}$, do Plano Integrado de Vigilância em Saúde das Populações Expostas aos Agrotóxicos ${ }^{42}$, do Protocolo de avaliação das intoxicações crônicas por agrotóxicos da SES do Paranáa ${ }^{7}$ e das Orientações técnicas para ações de vigilância de ambientes e processos de trabalho agrícola da SES da Bahia ${ }^{43}$.

Esta metodologia opera uma inversão fundamental em detrimento da lógica da busca pela "evidência" de agravos à saúde e a comprovação dos danos ambientais como motivos de ações de Vigilância, propõe uma plataforma para desencadear ações coletivas prévias ou de precaução aos problemas. Assim, a ênfase de uma Vigilância dos agravos e danos cede lugar para uma dos determinantes (produção agropecuária e uso de agrotóxicos), com base na possibilidade real de prever seus impactos, já constatados na literatura científica, ficando mais próxima de sua missão de intervir nos determinantes e condicionantes da saúde dos trabalhadores e população, eliminando os riscos e implantando outro modo de desenvolvimento, o sustentável.

Neste sentido, a Campanha Permanente Contra os Agrotóxicos e pela Vida ${ }^{38}$ desenvolve no Brasil e na América Latina, ações de Vigilância em saúde popular e participativa que propõe: cumprimento da legislação, proibir as pulverizações por avião, proibir o uso no Brasil dos agrotóxicos proibidos na União Europeia, fim dos subsídios públicos a esses venenos, implantar nos municípios as Vigilâncias à Saúde dos trabalhadores, do ambiente e dos expostos aos agrotóxicos, transição para a Agroecologia e busca do Desenvolvimento Sustentável. 
Esse artigo buscou apresentar elementos metodológicos com vistas a dar subsídios para ações de planejamento estratégico de vigilância à saúde dos trabalhadores, do ambiente e das populações expostas aos agrotóxicos.

Tornar efetivas as ações de vigilância à saúde no Brasil envolve processos e práticas interinstitucionais e participativas que incorporem informações de impactos sociais, ambientais e de saúde relacionados ao processo produtivo agropecuário e à exposição ocupacional, alimentar, ambiental e populacional aos agrotóxicos.

A estratégia metodológica proposta neste artigo contribuirá para a estimativa do consumo e do impacto dos agrotóxicos na saúde dos trabalhadores, na população, nos alimentos e no ambiente nas diversas regiões agrícolas do Brasil. A organização dos dados necessários certamente favorecerá a formação de redes de precaução, promoção e prevenção e motivará ações de vigilância dos determinantes dos riscos visando à transformação do atual processo produtivo agrícola na busca pelo desenvolvimento sustentável.
Essa estratégia corrobora com um modelo de vigilância em que devem ser fortalecidas as ações de promoção de saúde aliadas às estratégias de transição agroecológica ao se estabelecer ações sistemáticas e integradas de substituição dos agrotóxicos e fertilizantes químicos por outras práticas de aumento da produção de alimentos e controle de doenças agropecuárias.

\section{Colaboradores}

W Pignati coordenou as pesquisas e W Pignati, NP Oliveira e AMC da Silva participaram igualmente da elaboração, análises e discussões deste artigo.

\section{Agradecimentos}

Os autores agradecem ao $\mathrm{CNPq}$ e aos pesquisadores Frederico Peres e Josino C Moreira da Fiocruz e Sandro N Vieira da UFMT.

\section{Referências}

1. Carneiro FF, Pignati W, Rigotto RM, Augusto LGS, Rizollo A, Muller NM, Alexandre VP, Friedrich K, Mello MSC. Dossiê I: Um alerta sobre os impactos dos agrotóxicos nos alimentos e na saúde. Rio de Janeiro: Abrasco; 2012. 1a Parte

2. IBGE. Brasil, série histórica de área plantada e produção agrícola; safras 2005 a 2012. [acessado 2013 ago 15]. Disponível em: http://www.sidra.ibge.gov.br

3. Sindicato Nacional das Indústrias de Defensivos Agrícolas (Sindag). Dados de produção e consumo de agrotóxicos. [acessado 2013 dez 20]. Disponível em: http:// www.sindag.com.br

4. Augusto LGS, Carneiro FF, Pignati W, Rigotto RM, Rizollo A, Muller NM, Alexandre VP, Friedrich K, Mello MSC. Dossiê II da Abrasco: Um alerta sobre os impactos dos agrotóxicos no ambiente e na saúde. Rio de Janeiro: Abrasco; 2012. 2a Parte

5. Pignati W, Maciel RHMO, Rigotto RM. Saúde do trabalhador. In: Rouquayrol MZ. Epidemiologia \& Saúde. 7a ed. Rio de Janeiro: MedBook; 2013. p. 355-381.

6. Chaim A. Tecnologia de aplicação de agrotóxicos: fatores que afetam a eficiência e o impacto ambiental. In: Silva CMMS, Fay EF, organizadores. Agrotóxicos \& Am biente. Brasília: Embrapa; 2004. p. 289-317.

7. Pelaez V, Terra FHB, Silva LR. A regulamentação dos agrotóxicos no Brasil: entre o poder de mercado e a defesa da saúde e do meio ambiente. Revista de Economia $2011 ; 36(1): 27-48$.
8. Pignati W, Machado JMH, Cabral JF. Acidente rural ampliado: o caso das "chuvas" de agrotóxicos sobre a cidade de Lucas do Rio Verde. Cien Saude Colet 2007; 12(1):105-114.

9. Dos Santos LG, Lourencetti C, Pinto A, Pignati WA, Dores EFGC. Validation and application of an analytical method for determining pesticides in the gas phase of ambient air. J Environ Sci Health B 2011; 46(2):150162.

10. Correia FV, Moreira JC. Effects of glyfhosate and 2.4$\mathrm{D}$ on earthworms (Eisenia foetida) in laboratory tests. Bull Environ Contam Toxicol 2010; 85(3):264-268.

11. Palma DCA. Agrotóxicos em leite humano de mães residentes em Lucas do Rio Verde - MT [dssertação]. Cuiabá: Universidade Federal de Mato Grosso; 2011.

12. Moreira JC, Peres P, Simões AC, Pignati WA, Dores EF, Vieira S, Strussmann C, Mott T. Contaminação de águas superficiais e de chuva por agrotóxicos em uma região de Mato Grosso. Cien Saude Colet 2012; 17(6):1557-1568.

13. Belo MSS, Pignati W, Dores EGC, Moreira JC, Peres F. Uso de agrotóxicos na produção de soja do estado de Mato Grosso: um estudo preliminar de riscos ocupacionais e ambientais. Rev. bras. saúde ocup. 2012; 37(125):78-88.

14. ANVISA. Programa de Análise de Resíduos de Agrotóxicos em Alimentos (PARA). 2013. [acessado $2013 \mathrm{dez} 28$ ]. Disponível em: http://www.anvisa.gov.br 
15. Brasil. Ministério da Saúde (MS). Sistema Nacional de Notificação de Agravos - SINAN. Bancos de dados eletrônicos. [acessado 2014 set 19]. Disponível em: http:// dtr2004.saude.gov.br/sinanweb/

16. Cocco P. On the rumors about the silente spring: review of the scientific evidence linking ocupacional and environmental pesticide exposure to endocrine disruption health effects. Cad Saude Publica 2002; 18(2):379-402.

17. Moreira JCM, Peres F. É veneno ou remédio. Rio de Janeiro: Fiocruz; 2005.

18. Grisólia CK. Agrotóxicos, mutações, câncer \& reprodução. Brasília: editora Universidade de Brasília; 2005.

19. Faria ET, Faria NMX, Rosa JAR, Faccini LA. Intoxicações por agrotóxicos entre trabalhadores rurais de fruticultura, Bento Goncalves, RS. Rev Saude Publica 2009; 43(2):335-344.

20. Cunha MLON. Mortalidade por câncer e a utilização de pesticidas no estado de Mato Grosso [dissertação], São Paulo: Faculdade de Medicina da Santa Casa de São Paulo; 2010.

21. Pignati WA, Machado JMH. O agronegócio e seus impactos na saúde dos trabalhadores e da população do Estado de Mato Grosso. In: Gomez CM, Machado JHM, Pena PG, organizadores. Saúde do trabalhador na sociedade brasileira contemporânea. Rio de Janeiro: Fiocruz; 2011. p. 245-272.

22. Fávero KAS. Pulverizações de agrotóxicos nas lavouras de Lucas do Rio Verde e os agravos respiratórios em crianças $<05$ anos [dissertação]. Cuiabá: Universidade Federal de Mato Grosso; 2011.

23. Bombardi LM. Agrotóxico e agronegócio: arcaico e moderno se fundem no campo brasileiro. Relatório da Rede Social de Justiça e Direitos Humanos 2012. p.7587. [acessado 2014 set 19]. Disponível em: http://reporterbrasil.org.br/documentos/DH_relatorio_2012. pdf\#page $=75$

24. Uecker ME. Exposição aos agrotóxicos no Mato Grosso e malformações congênitas em menores de 05 anos atendidas em Hospitais de Cuiabá [dissertação]. Cuiabá: Universidade Federal de Mato Grosso; 2012.

25. Oliveira NP. Malformações congênitas e o uso de agrotóxicos em municípios de Mato Grosso, período de 2000 a 2009 [dissertação]. Cuiabá: Universidade Federal de Mato Grosso; 2012.

26. Curvo HRM, Pignati WA, Pignatti MG. Morbi mortalidade por câncer infantojuvenil associada ao uso agrícola de agrotóxicos no Estado de MT- Brasil. Cad. Saúde Coletiva 2013; 21(1):10-17.

27. Paraná. Secretaria de Estado da Saúde (SES). Protocolo de avaliação das intoxicações crônicas por agrotóxicos. Curitiba: SES-PR; 2013.

28. Instituto de Defesa Agropecuária do Mato Grosso (INDEA-MT). Relatório/Planilha de Dados do Sistema de Informação de Agrotóxicos dos anos de 2005 a 20012. [banco de dados eletrônico]. Cuiabá: INDEA-MT; 2013.

29. Empresa Brasileira de Pesquisa, Assistência e Extensão Rural (EMPAER). Calendário Agrícola de 2012. [acessado 2013 mar 21]. Disponível em: http://www.empaer. $\mathrm{mt}$.gov.br/arquivos/arquivos.asp? $\operatorname{cod}=4$

30. Itho SF. Rotina de atendimento do intoxicado. $3^{\mathrm{a}} \mathrm{ed}$. Vitória: Toxcen; 2007.
31. Schvartsman S. Intoxicações por pesticidas. In: Schvartsman S. Intoxicações agudas. $4^{\text {a }}$ ed. São Paulo: Sarvier; 2001. p. 250-297.

32. Anvisa. Resolução da Diretoria Colegiada - RDC no 10 , de 22 de fevereiro de 2008. Dispõe sobre reavaliação toxicológica de ingredientes ativos. Diário Oficial da União 2008; 25 fev.

33. United States. Environmental Protection Agency (USEPA). Tipos de Pesticidas, Classificação Toxicológica. [acessado 2014 abr 2]. Disponível em: http://www.epa. gov/pesticides/about/types.htm

34. Augusto LG, Carneiro F, Pignati W, Rigotto RM. Dossiê II: Agrotóxicos e ambiente. Rio de Janeiro: Abrasco; 2012. 2a Parte

35. Rigotto RM, Augusto LGS, Carneiro F, Pignati W. Dossiê III: Agrotóxicos: construindo a ecologia de saberes. Rio de Janeiro: Abrasco; 2012. 3a Parte

36. Porto MFS, Soares WL. Modelo de desenvolvimento, agrotóxicos e saúde: um panorama da realidade agrícola brasileira e propostas para uma agenda de pesquisa inovadora. Rev. Bras. Saúde Ocup. 2012, 37(125):17-50.

37. Machado JHM. Perspectivas e pressupostos da Vigilância em Saúde do Trabalhador no Brasil. In: Gomez CM, Machado JHM, Pena P. Saúde do Trabalhador na sociedade brasileira contemporânea. Rio de Janeiro: Fiocruz; 2011. p. 67-86.

38. Campanha Permanente Contra os Agrotóxicos e pela Vida. Boletim Informativo da Campanha. [acessado 2014 maio 30]. Disponível em: http://www.contraos agrotoxicos.org

39. Associação Nacional de Agroecologia. Carta Política aprovada em 19 de maio de 2014 no III Encontro $\mathrm{Na}$ cional de Agroecologia. [acessado 2014 maio 30]. Disponível em: http://aspta.org.br/2014/05/carta-politicado-iii-encontro-nacional-de-agroecologia/

40. Brasil. Ministério da Saúde (MS). Portaria no 1.823, de 23 de agosto de 2012. Institui a Política Nacional de Saúde do Trabalhador e da Trabalhadora. Diário Oficial da União 2012; 24 ago.

41. Brasil. Ministério da Saúde (MS). Portaria nº 2.866, de 02 de dezembro de 2011. Institui a Política Nacional de Saúde Integral das Populações do Campo e da Floresta (PNSIPCF). Diário Oficial da União 2011; 3 dez.

42. Brasil. Ministério da Saúde (MS). Diretrizes do Plano Integrado de Vigilância a Saúde das Populações Expostas aos Agrotóxicos. 2012. 133p. [acessado 2014 maio 30]. Disponível em: http://www.renastonline.org/sites/ default/files/arquivos/recursos/Documento\%20orientador\%20Vig\%20Pop\%20Agrotox_Vigipeq_completo2013.pdf

43. Bahia. Secretaria Estadual de Saúde. Manual de orientações técnicas para ações de vigilância de ambientes e processos de trabalho agrícola. [acessado 2014 maio 30]. Disponível em: www.suvisa.ba.gov.br/saude_trabalhador/publicacoes/manuais

Artigo apresentado em 29/08/2014

Aprovado em 29/08/2014

Versão final apresentada em 09/09/2014 